\title{
Location of correction within the lumbar spine impacts acute adjacent-segment kyphosis
}

\author{
Renaud Lafage, MS, ${ }^{1}$ Ibrahim Obeid, MD, ${ }^{2}$ Barthelemy Liabaud, MD, ${ }^{1}$ Shay Bess, MD, ${ }^{3}$ \\ Douglas Burton, MD, Justin S. Smith, MD, PhD, ${ }^{5}$ Cyrus Jalai, BS, ${ }^{3}$ Richard Hostin, MD, ${ }^{6}$ \\ Christopher I. Shaffrey, MD, ${ }^{5}$ Christopher Ames, MD, ${ }^{7}$ Han Jo Kim, MD, ${ }^{1}$ Eric Klineberg, MD, ${ }^{8}$ \\ Frank Schwab, MD, ${ }^{1}$ Virginie Lafage, $\mathrm{PhD},{ }^{1}$ and the International Spine Study Group

\begin{abstract}
${ }^{1}$ Spine Service, Hospital for Special Surgery, New York, New York; ${ }^{2}$ Spine Unit 1, CHU Pellegrin, Bordeaux, France; ${ }^{3}$ Spine Division, Department of Orthopaedics, NYU Langone Medical Center, New York, New York; " ${ }^{4}$ epartment of Orthopaedic Surgery, University of Kansas Medical Center, Kansas City, Kansas; ${ }^{5}$ Department of Neurosurgery, University of Virginia, Charlottesville, Virginia; ${ }^{6}$ Department of Orthopaedic Surgery, Baylor Scoliosis Center, Plano, Texas; ' Department of Neurosurgery, San Francisco Medical Center, University of California, San Francisco; and ${ }^{8}$ Department of Orthopedic Surgery, University of California, Davis, Sacramento, California
\end{abstract}

\begin{abstract}
OBJECTIVE The surgical correction of adult spinal deformity (ASD) often involves modifying lumbar lordosis (LL) to restore ideal sagittal alignment. However, corrections that include large changes in LL increase the risk for development of proximal junctional kyphosis (PJK). Little is known about the impact of cranial versus caudal correction in the lumbar spine on the occurrence of PJK. The goal of this study was to investigate the impact of the location of the correction on acute PJK development.
\end{abstract}
METHODS This study was a retrospective review of a prospective multicenter database. Surgically treated ASD pa- tients with early follow-up evaluations ( 6 weeks) and fusions of the full lumbosacral spine were included. Radiographic parameters analyzed included the classic spinopelvic parameters (pelvic incidence [PI], pelvic tilt [PT], PI-LL, and sagittal vertical axis [SVA]) and segmental correction. Using Glattes' criteria, patients were stratified into PJK and noPJK groups and propensity matched by age and regional lumbar correction ( $\triangle \mathrm{PI}-\mathrm{LL})$. Radiographic parameters and segmen- tal correction were compared between PJK and noPJK patients using independent t-tests.

RESULTS After propensity matching, 312 of 483 patients were included in the analysis (mean age 64 years, $76 \%$ women, $40 \%$ with PJK). There were no significant differences between PJK and noPJK patients at baseline or postoperatively, or between changes in alignment, with the exception of thoracic kyphosis (TK) and $\Delta T K$. PJK patients had a decrease in segmental lordosis at L4-L5-S1 $\left(-0.6^{\circ}\right.$ vs $\left.1.6^{\circ}, p=0.025\right)$, and larger increases in segmental correction at cranial levels L1-L2-L3 $\left(9.9^{\circ}\right.$ vs $\left.7.1^{\circ}\right)$, T12-L1-L2 $\left(7.3^{\circ}\right.$ vs $\left.5.4^{\circ}\right)$, and T11-T12-L1 $\left(2.9^{\circ}\right.$ vs $\left.0.7^{\circ}\right)($ all $p<0.05)$.

CONCLUSIONS Although achievement of an optimal sagittal alignment is the goal of realignment surgery, dramatic lumbar corrections appear to increase the risk of PJK. This study was the first to demonstrate that patients who developed PJK underwent kyphotic changes in the L4-S1 segments while restoring LL at more cranial levels (T12-L3). These findings suggest that restoring lordosis at lower lumbar levels may result in a decreased risk of developing PJK.

https://thejns.org/doi/abs/10.3171/2018.6.SPINE161468

KEYWORDS adult spinal deformity; proximal junctional kyphosis; lumbar correction; segmental change; lumbar fusion; overcorrection

A DULT spinal deformity (ASD) is an increasingly recognized source of pain and disability in our aging population. Increased ASD severity, characterized by a flattening of lumbar lordosis (LL) ${ }^{1}$ as well as an anterior trunk inclination, ${ }^{23}$ corresponds to worsened patient-reported health-related quality-of-life (HRQOL) scores. .,23 $^{2}$

When the severity of ASD starts to negatively impact patients' lives and livelihoods, symptomatic and definitive treatment should be identified and pursued. Fortunately, the

ABBREVIATIONS ASD = adult spinal deformity; FH = femoral head; HRQOL = health-related quality of life; LIV = lower instrumented vertebra; LL = lumbar lordosis; $\mathrm{PI}=$ pelvic incidence; PJK = proximal junctional kyphosis; PT = pelvic tilt; SVA = sagittal vertical axis; TK = thoracic kyphosis; TPA = T1-pelvic angle; UIV = upper instrumented vertebra.

SUBMITTED December 20, 2016. ACCEPTED June 5, 2018.

INCLUDE WHEN CITING Published online October 26, 2018; DOI: 10.3171/2018.6.SPINE161468. 
majority of symptomatic ASD patients can be sufficiently managed initially using nonoperative treatment. However, for those with severe pain or disability, or those who are not responding to conservative treatment, the symptoms may warrant surgical treatment. Smith et al. reported that ASD patients who underwent nonoperative treatment were less likely to improve at the 1-year follow-up than surgically treated patients. ${ }^{35}$ With a surgical approach, direct decompression of the neural elements, a known pain generator, is critical in providing a satisfactory improvement in patient HRQOL scores. Additionally, when possible, spinopelvic alignment should be restored, because extensive evidence has been reported supporting the significant correlation between sagittal profile restoration and improved HRQOL. ${ }^{1,32}$

Several operative techniques have successfully reached similar clinical outcomes for ASD patients. A recent study by Park et al. demonstrated similar clinical improvement between circumferential minimally invasive surgery and minimally invasive lateral interbody fusion with open posterior instrumented fusion. ${ }^{27}$ The combined anterior and posterior approach was also reported to be as effective as the posterior-only approach in ASD patients. ${ }^{11}$ For ASD patients requiring aggressive corrections, 3-column osteotomies have revealed promising results. ${ }^{5,7}$ However, despite satisfactory outcomes, revisions following correction surgery continue to occur. Among all complications requiring revision surgery, adjacent segmental pathologies, e.g., proximal junctional kyphosis (PJK), are among the most common and critical pathologies. ${ }^{2,11}$

Risk factors predicting adjacent segmental pathology following ASD correction surgery have attracted considerable interest. Early in 1994, Lowe and Kasten recognized that overcorrection (>50\%) may lead to consequential kyphotic deformity. ${ }^{24}$ This theory was reaffirmed by recent studies demonstrating that changes in LL $>30^{\circ}$, large postoperative LLs, or large corrections of the sagittal vertical axis (SVA) may all lead to the occurrence of PJK. ${ }^{16,25}$ As previous studies have highlighted the importance of appropriately correcting LL, a thorough understanding of lumbar regional and segmental profiles may, therefore, benefit the surgical decision-making process.

To achieve the goal of properly restoring LL, the natural shape of the lumbar region and its associated factors should be examined. Pelvic incidence (PI), the presentation of pelvic morphology, has been demonstrated as a fundamental determinant of LL. In addition to caudal factors, LL was also recently found to adapt to cranial alignment (large and rigid thoracic kyphosis [TK]). ${ }^{34}$ For optimal restoration of lordosis, both regional and segmental alignment should be recognized. According to previous efforts regarding the natural shape of LL, $60 \%$ of the overall LL is located in the L4-S1 motion segment. ${ }^{8,12}$ Roussouly et al., therefore, proposed 4 lumbar types based on the pelvic morphology and the location of the apex of LL. ${ }^{31}$ In clinical applications, however, the importance of restoring segmental LL has not been illustrated. In this study we sought to analyze the location of the correction in the lumbar area following realignment ASD surgery and to compare the lumbar correction between patients with and without signs of radiographic PJK.

\section{Methods}

\section{Patient Population}

This study was a retrospective review of a prospective multicenter database of patients with ASD. After IRB approval at each of the 11 participating sites across the US, patients were enrolled in this database if they met the following criteria: age $>18$ years and spinal deformity confirmed by at least one of the following measures: scoliosis Cobb angle $>20^{\circ}$, SVA $>5 \mathrm{~cm}$, pelvic tilt $(\mathrm{PT})>25^{\circ}$, and TK $>60^{\circ}$. For this specific study, only patients treated surgically with a fusion extending from the pelvis (sacrum or ilium) to at least L1 were included.

\section{Data Collection and Radiographic Parameters}

Demographics (e.g., age, sex, and BMI) and surgical parameters (e.g., upper and lower instrumented vertebrae [UIV and LIV], and number of levels fused) were collected.

Full-length, freestanding lateral and anteroposterior spine radiographs were collected preoperatively and postoperatively. Identification and mapping of various anatomical landmarks were performed using validated software (SpineView, ENSAM Laboratory of Biomechanics ${ }^{3}$ ) at a central location. Using this spatial data, the parameters of interest were then calculated using MATLAB (MATLAB 2015b, MathWorks). The radiographic parameters included the following classic spinopelvic parameters: PT, PI, LL between S1 and L1 (LL), mismatch between PI and LL (PI-LL), TK between T4 and T12 (TK), SVA, and T1-pelvic angle (TPA). ${ }^{29}$ In addition, the segmental alignment-the relative position of a vertebra with respect to the location of its 2 adjacent vertebrae-was calculated at each level (Fig. 1). ${ }^{19,38}$ Changes in alignment were evaluated by subtracting the preoperative alignment from the postoperative alignment. A negative change in alignment was defined as a kyphotic change and/or an anterior progression.

Radiographic PJK was defined using the following criteria described by Glattes et al.: ${ }^{10}$ a kyphotic angle > $10^{\circ}$ between UIV and 2 levels above UIV and a kyphotic change $>10^{\circ}$ from the baseline between UIV and 2 levels above UIV.

\section{Statistical Analysis}

The collected demographic, surgical, and radiographic data were described and analyzed at baseline and immediate postoperative follow-up. Changes in radiographic alignment were also investigated, including a preoperative to postoperative analysis of sagittal alignment and the rate of radiographic PJK.

Patients were stratified into 5 groups based on the preoperative to postoperative degree of change in LL: decrease in LL (kyphotic change $>5^{\circ}$ ), stable (change between $-5^{\circ}$ and $5^{\circ}$ ), $5^{\circ}-15^{\circ}$ increase (lordotic change of $5^{\circ}-15^{\circ}$ ), $15^{\circ}-25^{\circ}$ increase (lordotic change of $15^{\circ}-25^{\circ}$ ), and more than $25^{\circ}$ increase (lordotic change $>25^{\circ}$ ). The segmental change at each level was described for each stratified change in LL group and then compared using ANOVA.

To mitigate the influence of confounding variables on 


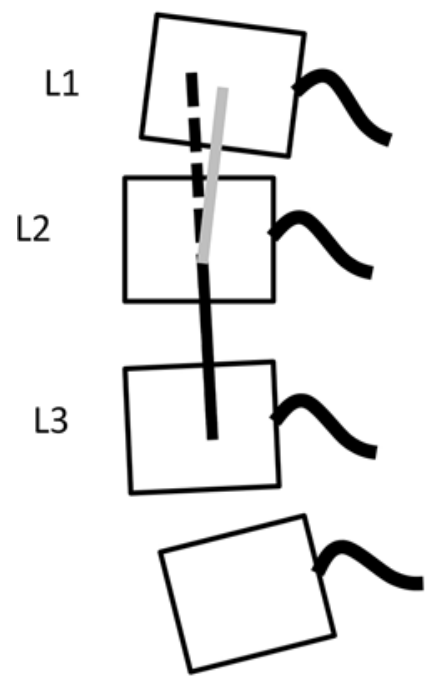

Pre

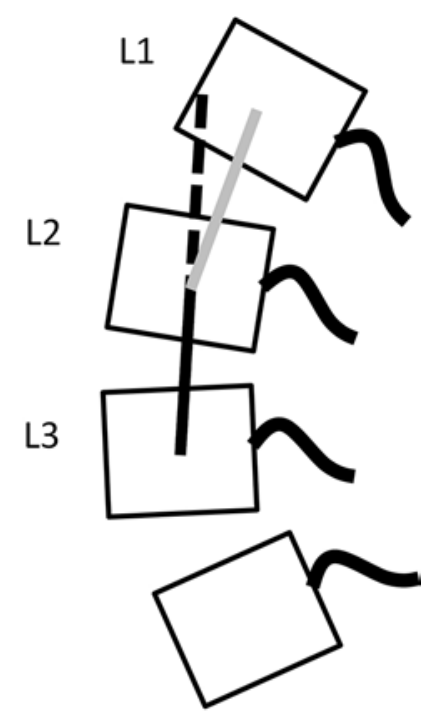

Post
FIG. 1. Segmental change between 2 adjacent segments using L3-L2-L1 as an example. The change was calculated by subtracting the angle between L1-L2 and L2-L3 preoperatively (Pre) (black line vs light gray line) from L1-L2 and L2-L3 postoperatively (Post). If the difference is negative, the segmental change is kyphotic, otherwise it is a lordotic change.

analyzing factors surrounding the development of PJK, patients with a radiographic PJK were matched to postoperative patients without radiographic PJK (noPJK group) by age, preoperative TPA (measurement of the preoperative global deformity), and change in LL using a propensity score. ${ }^{18,39}$ This matching was performed by use of logistical regression and stratification to obtain 2 groups of equal numbers of patients without significant differences in age, preoperative alignment, or total correction within the lumbar spine. Global and segmental changes in sagittal alignment were then compared between PJK and noPJK patients using a paired t-test. Finally, substratified groups based on the location of the UIV (lower thoracic, UIV between L1 and T8; upper thoracic, UIV between T7 and T1) were also analyzed in a similar way.

\section{Results}

\section{Patient Population}

The study population included 483 patients, $78 \%$ of whom were women. The mean age was $62.7 \pm 9.9$ years, the mean BMI was $28.1 \pm 5.7 \mathrm{~kg} / \mathrm{m}^{2}$, and the mean followup period was $6.9 \pm 3$ weeks.

Patients had a mean number of $11.9 \pm 3.6$ levels fused, ranging from 6 to 18. Further analysis revealed that the UIV location was T10 for $32.9 \%(\mathrm{n}=159)$, T4 for $18.8 \%$ $(\mathrm{n}=91), \mathrm{T} 3$ for $14.7 \%(\mathrm{n}=71)$, and T11 for $11.2 \%(\mathrm{n}=54)$ of the cases. The majority of patients received fusion to the ilium (95.4\%); only a few underwent fusions ending inferiorly at the sacrum (22 cases).

Postoperatively, patients experienced significant improvements in every sagittal parameter from baseline; PI-LL decreased from $21.2^{\circ} \pm 19.2^{\circ}$ to $1.5^{\circ} \pm 13.7^{\circ}$, PT decreased from $26.1^{\circ} \pm 10.1^{\circ}$ to $20.1^{\circ} \pm 9.8^{\circ}$, and SVA decreased from $8.5 \mathrm{~cm}$ to $2.5 \mathrm{~cm}$ (all p $<0.001$ ). The mean
TABLE 1. Pre- and postoperative sagittal alignment and pre- to postoperative comparison

\begin{tabular}{lccr}
\hline \multicolumn{1}{c}{ Parameter } & Preop & Postop & p Value \\
\hline $\mathrm{PI}\left({ }^{\circ}\right)$ & $55.4 \pm 12.4$ & $55.3 \pm 12.2$ & 0.105 \\
\hline $\mathrm{PT}\left({ }^{\circ}\right)$ & $26.1 \pm 10.1$ & $20.1 \pm 9.8$ & $<0.001$ \\
\hline Lumbar mismatch, PI-LL $\left(^{\circ}\right)$ & $21.2 \pm 19.2$ & $1.5 \pm 13.7$ & $<0.001$ \\
\hline TK, T4-12 $\left(^{\circ}\right)$ & $-31.1 \pm 18.2$ & $-42.3 \pm 15.2$ & $<0.001$ \\
\hline SVA $(\mathrm{mm})$ & $85 \pm 73$ & $25 \pm 48$ & $<0.001$ \\
\hline TPA $\left({ }^{\circ}\right)$ & $26.2 \pm 12.1$ & $16 \pm 9.8$ & $<0.001$ \\
\hline
\end{tabular}

Every sagittal parameter (mean $\pm \mathrm{SD}$ ) significantly decreased from preoperatively to postoperatively.

pre- and postoperative sagittal alignment values are summarized in Table 1. The rate of postoperative radiographic PJK was $40 \%(n=193)$.

\section{Comparing Segmental Change by LL Group}

Stratifying the 483 patients by the pre- to postoperative changes in LL resulted in the following distribution: 27 patients in the $\Delta \mathrm{LL}<-5^{\circ}$ group, 66 patients in the $-5^{\circ}<$ $\Delta \mathrm{LL}<5^{\circ}$ group, 103 patients in the $5^{\circ}<\Delta \mathrm{LL}<15^{\circ}$ group, 125 patients in the $15^{\circ}<\Delta \mathrm{LL}<25^{\circ}$ group, and 162 patients in the $\Delta \mathrm{LL}>25^{\circ}$ group.

The mean value for each segmental change in each group was computed. A graphical representation of these changes within the lumbar and thoracolumbar regions illustrates the distribution of the pre- to postoperative degree of segmental changes in each $\Delta \mathrm{LL}$ group at each vertebral level (Fig. 2). Most of the correction was performed within the upper part of the lumbar region (L3 to L1).

\section{Propensity Match}

Propensity-matched noPJK and PJK groups consisted of 156 patients each. By design, patients with and without radiographic PJK had similar ages (noPJK $63.9 \pm 9.5$ vs PJK 64.0 \pm 9.0 years, $\mathrm{p}=0.919)$, preoperative TPA $\left(26.7^{\circ}\right.$ $\pm 11.7^{\circ}$ vs $26.7^{\circ} \pm 12.9^{\circ}, \mathrm{p}=1$ ), and similar corrections of LL $\left(\Delta \mathrm{LL}: 21.6^{\circ} \pm 15.9^{\circ}\right.$ vs $21.0^{\circ} \pm 15.9^{\circ}, \mathrm{p}=0.726$; Fig. $3)$. In addition, no significant differences between the two groups in terms of changes in sagittal alignment were noted $\left(\Delta \mathrm{PT}:-7.2^{\circ} \pm 8.4^{\circ}\right.$ vs $-5.9^{\circ} \pm 7.6^{\circ}, \mathrm{p}=0.146 ; \Delta \mathrm{SVA}:-62$ $\mathrm{mm} \pm 65 \mathrm{~mm}$ vs $-67 \mathrm{~mm} \pm 70 \mathrm{~mm}, \mathrm{p}=0.465$; Table 2).

Segmental change analysis in the PJK and noPJK groups revealed significant differences at several levels. PJK patients displayed significantly smaller lordotic changes at the lowest lumbar level (S1, L5, L4: $-0.6^{\circ}$ vs $1.6^{\circ}, \mathrm{p}=0.025$ ) but significantly greater lordotic changes at the upper lumbar and thoracolumbar levels (L3-L2-L1: 9.9 ${ }^{\circ}$ vs $7.1^{\circ}$; L2-L1-T12: $7.3^{\circ}$ vs $5.4^{\circ}$; L1-T12-T11: $2.9^{\circ}$ vs $0.7^{\circ}$; all $\mathrm{p}<0.05$ ). In addition, PJK patients experienced a greater kyphotic change than noPJK patients at two distinct levels (Fig. 4). These two levels of greater kyphotic change were associated with the two most common UIV positions.

Stratification by UIV position demonstrated that PJK patients had a more kyphotic change at the UIV level (by design) with a lordotic change higher on the lumbar spine. 


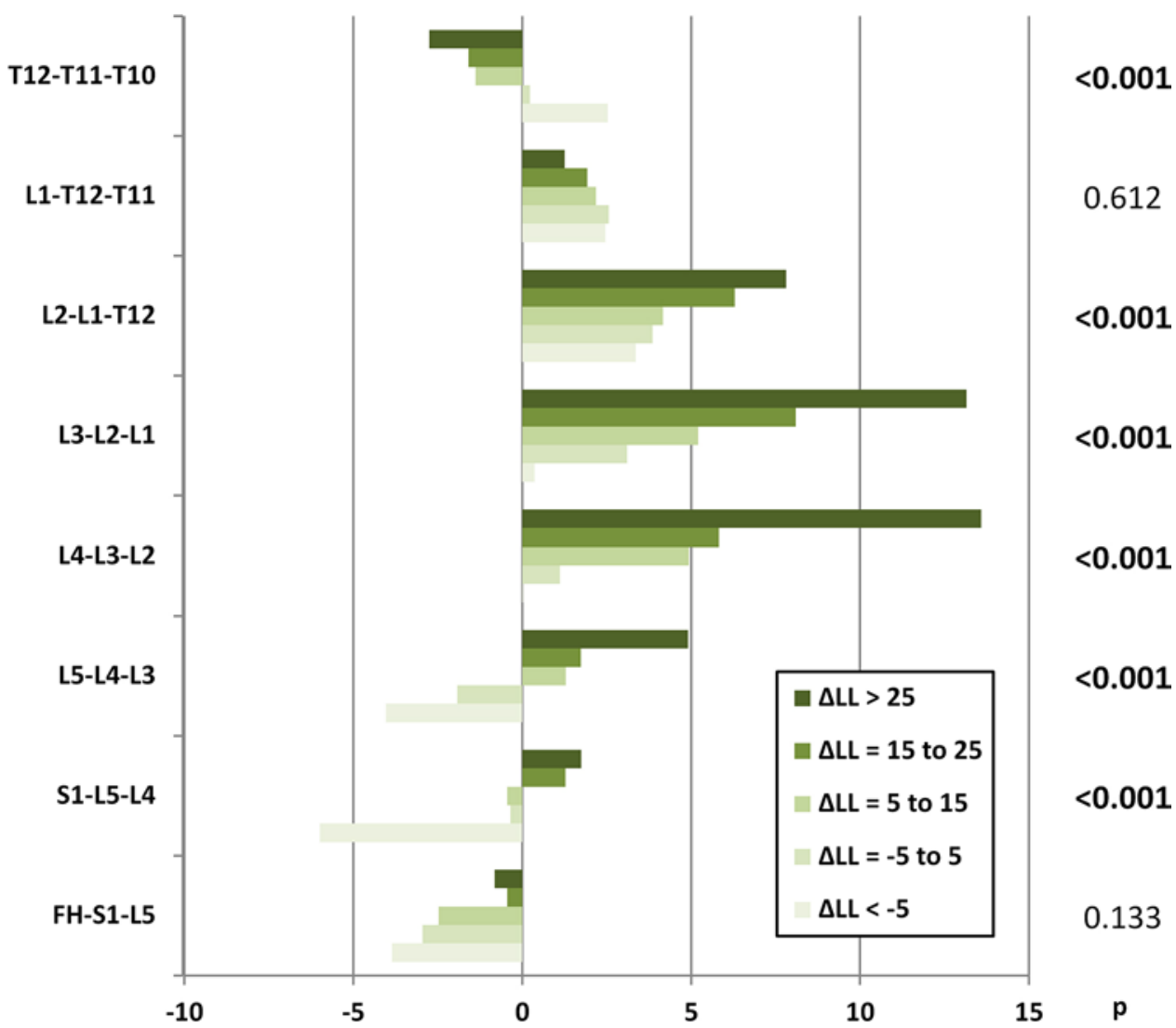

FIG. 2. Segmental change (in degrees) within the lumbar spine according to LL correction group. No significant difference was found in segmental change at the lower part of the lordosis (FH-S1-L5) or at the thoracolumbar junction (L1-T12-T11). FH = femoral head. Figure is available in color online only.
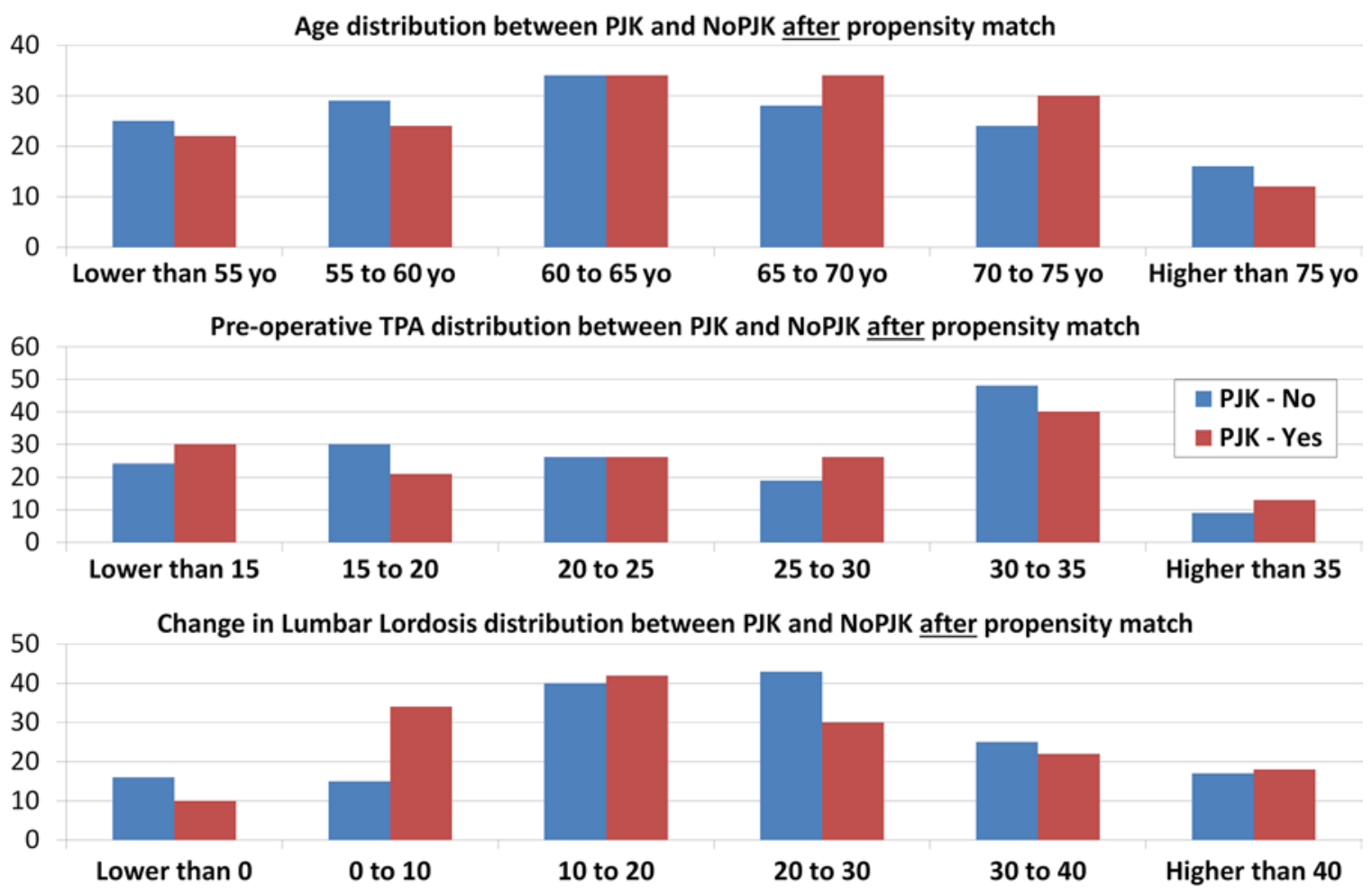

FIG. 3. Distribution of age (in years), preoperative TPA (in degrees), and change (in degrees) in LL between PJK and noPJK after a propensity match. yo = years old. Figure is available in color online only. 
TABLE 2. Comparing PJK versus noPJK groups after propensity matching

\begin{tabular}{lccc}
\hline \multicolumn{1}{c}{ Parameter } & NoPJK $(n=156)$ & PJK $(n=156)$ & $p$ Value \\
\hline Age $(\mathrm{yrs})$ & $63.9 \pm 9.5$ & $64.0 \pm 9.0$ & 0.919 \\
\hline$\Delta \mathrm{PT}\left({ }^{\circ}\right)$ & $-7.2 \pm 8.4$ & $-5.9 \pm 7.6$ & 0.146 \\
\hline$\Delta \mathrm{LL}\left({ }^{\circ}\right)$ & $21.6 \pm 15.9$ & $21.0 \pm 15.9$ & 0.726 \\
\hline$\Delta \mathrm{PI}-\mathrm{LL}\left({ }^{\circ}\right)$ & $-21.7 \pm 15.7$ & $-21.3 \pm 16.5$ & 0.830 \\
\hline$\Delta \mathrm{TK}\left({ }^{\circ}\right)$ & $-11.4 \pm 11.5$ & $-12.8 \pm 17.9$ & 0.416 \\
\hline$\Delta \mathrm{SVA}(\mathrm{mm})$ & $-62 \pm 65$ & $-67 \pm 70$ & 0.465 \\
\hline$\Delta \operatorname{TPA}\left({ }^{\circ}\right)$ & $-11.3 \pm 9.73$ & $-10.9 \pm 10.6$ & 0.760 \\
\hline
\end{tabular}

No significant differences in change $(\Delta)$ in alignment between PJK and noPJK were noted. Data in each group are given as mean \pm SD.

\section{Lower Thoracic UIV}

PJK patients had a significantly larger lordotic change in the upper lumbar segments than did noPJK patients (L3-L2-L1: $6.3^{\circ} \pm 7.5^{\circ}$ vs $9.7^{\circ} \pm 9.3^{\circ}, \mathrm{p}=0.011$; L2-L1-
T12: $3.6^{\circ} \pm 5.7^{\circ}$ vs $6.1^{\circ} \pm 6.8^{\circ}, \mathrm{p}=0.011 ; \mathrm{L} 1-\mathrm{T} 12-\mathrm{T} 11:-1.0^{\circ}$ $\pm 4.6^{\circ}$ vs $1.1^{\circ} \pm 6.2^{\circ}, \mathrm{p}=0.017$; Fig. 5 ).

\section{Upper Thoracic UIV}

Similarly, PJK patients experienced significantly larger lordotic changes in the thoracolumbar levels and greater kyphotic changes in the UIV area compared to noPJK patients (Fig. 5). Interestingly, PJK patients also experienced a kyphotic change at the lowest lumbar level (S1-L5-L4: $-1.7^{\circ}$ vs $\left.1.5^{\circ}, \mathrm{p}=0.028\right)$.

\section{Discussion}

The importance of restoring regional LL has been recognized by the spine community; however, the way in which segmental LL influences adjacent alignment is frequently overlooked. This novel study focused on both regional and segmental correction of LL in ASD patients, showing that PJK may be associated with the location of LL correction. After matching patients by age and degree

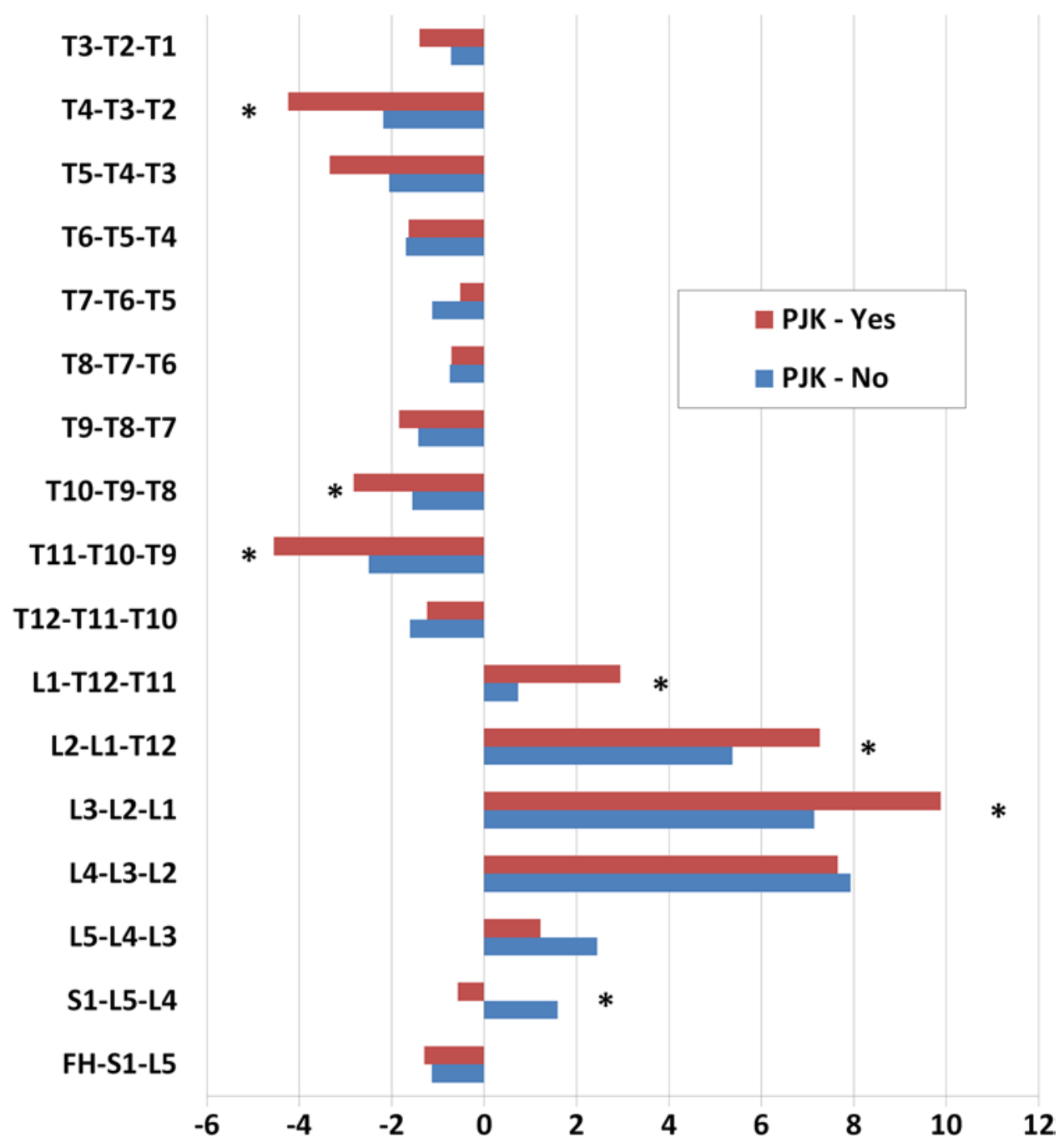

FIG. 4. Comparison of segmental changes (in degrees) between PJK and noPJK. PJK patients experienced a significantly larger lordotic change in the upper part of the lumbar spine and a significantly more kyphotic change at the 2 UIV areas (T10 and T4). An asterisk denotes a significant difference between PJK and noPJK patients $(p<0.05)$. Figure is available in color online only. 


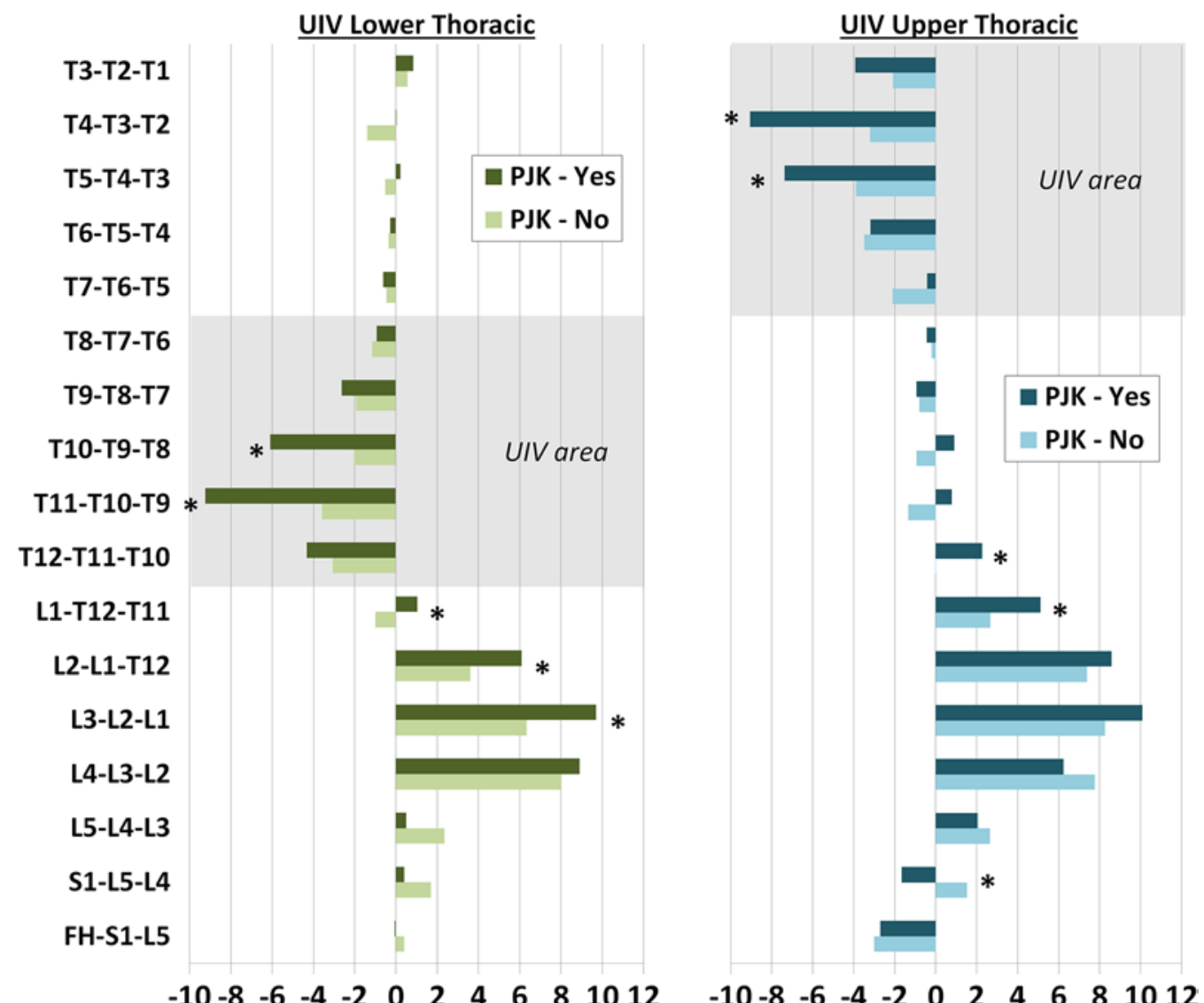

FIG. 5. Comparison of the segmental correction (in degrees) between PJK and noPJK after substratification by UIV position. PJK patients experienced a larger lordotic change in the proximal lumbar levels (correction) associated with a kyphotic change at the UIV area (PJK). An asterisk denotes a significant difference between PJK and noPJK patients $(p<0.05)$. Figure is available in color online only.

of PI-LL correction, a comparison between PJK and nonPJK patients revealed significantly more lordosis correction at both the upper level of LL and the UIV area in PJK patients. To eliminate the impact of UIV location, patients were stratified into lower thoracic and higher thoracic UIV subgroups, and the comparison between PJK and non-PJK patients within subgroups showed similar results, demonstrating the importance of appropriate proximal and distal LL correction.

The necessity of LL correction has been well described over the last 30 years. Recently, after general recognition of the importance of sagittal spinal alignment, PI-LL modifiers in the SRS-Schwab ASD classification ${ }^{33}$ demonstrated a correlation to HRQOL. Thus, failing to restore normal PI-LL leads to unfavorable clinical outcomes, ${ }^{20,23,26}$ e.g., constant pain and disability, mechanical implant failure, PJK, and even preventive revision surgery. Therefore, adequate correction is of utmost importance in the surgical treatment of ASD patients; both over- and undercorrection of LL may cause suboptimal consequences. According to Glassman et al., the undercorrection of LL will lead to suboptimal alignment and decreased HRQOL. ${ }^{9}$ Similarly, Rothenfluh et al. addressed the occurrence of adjacent segmental degeneration following undercorrection of LL with biomechanical proof, confirming at the same time the $10^{\circ}$ threshold for PI-LL regarding the risk of adjacent segmental degeneration..$^{30}$ Overcorrection of LL, on the other hand, also causes unfavorable clinical outcomes such as PJK and implant failure. ${ }^{21,36}$

Radiographic PJK has been receiving increased attention by the spine community over the past several years. In some extreme cases, revision surgery is required for severe or progressive PJK generating severe pain, disability, and/ or neurological complications. The occurrence of PJK is a multifactorial problem with numerous ongoing studies aiming at revealing its predictors. The overcorrection of LL has been documented as one of the best predictors of developing PJK. Maruo et al. proposed that a change in LL of more than $30^{\circ}$ is a risk factor for PJK..$^{25}$ This result was echoed by a study by Kim et al. that identified both larger postoperative LLs and larger SVA corrections as risk factors. ${ }^{17}$ A similar conclusion was also drawn by Yagi et al., proposing a large SVA change as a predictor for PJK. ${ }^{39}$ Recently, Lafage et al. provided additional evidence for the overcorrection theory with a virtual model, indicating that PJK was a reciprocal change from an overambitious correction threshold. ${ }^{21}$

However, all previous studies investigated the pre- and postoperative change in global alignment. In the current study, the proximal segmental correction of LL was asso- 
ciated with the occurrence of PJK, which has not yet been reported. Greater correction in the upper lumbar section predisposed patients to develop PJK, independent of the location of UIV. As found by previous studies, ${ }^{8,12}$ the upper lumbar section only contributed to less than $40 \%$ of total lordosis. Considering that the total LL correction was matched between PJK and noPJK patients, a more aggressive correction of upper LL level resulted in an "unnatural" lordosis and a relative overcorrection in the proximal lumbar section (or thoracolumbar region) associated with an undercorrection of the caudal LL. As a reciprocal adaptation, radiographic PJK may, therefore, occur to compensate for the regional overcorrection.

Instead of restoring the caudal LL-which accounts for $60 \%$ of total LL in the normal population-a kyphotic change or no change in lordosis at the most caudal level (femoral head [FH]-S1-L5 change) was observed. In addition, PJK patients showed significantly more caudal kyphotic changes at S1-L5-L4. In patients undergoing 3-column osteotomies, the lumbar spine is pushed forward when closing the osteotomy site; this forces the caudal levels to be relatively kyphotic with respect to the osteotomy level, creating a compensatory reverse curve. Therefore, a smaller caudal lordotic change represents a greater cranial lordotic correction in a given total LL correction. Following this explanation, we also found that most of the correction happened between the upper segments of the lumbar region (L4-L3-L2 and L3-L2-L1), probably because L3 is the most common level for a 3-column osteotomy. ${ }^{6}$ According to Roussouly's classification, the apex of LL is not always the same for all subjects. ${ }^{31}$ Nevertheless, the lumbar apex of ASD patients after a 3-column osteotomy would be the osteotomy level and may, therefore, differ from the natural lumbar apex.

The current study showed that overcorrection at the upper lumbar level predisposed patients to PJK occurrence following ASD correction surgery, emphasizing the importance of proper LL restoration. Previous efforts toward guiding LL restoration have been widely recognized, e.g., ideal PI-LL mismatch within $10^{\circ}$. However, the use of criteria such as these needs to evolve as our understanding of sagittal alignment improves. Recent work by Inami et al. demonstrated the necessity of determining if PI is extremely large or extremely small so that the PI-LL could be restored accordingly. ${ }^{15}$ Moreover, the impact of age on sagittal alignment should also be considered during surgical planning, as demonstrated by Lafage et al. ${ }^{22}$ According to the current data, LL restoration should be performed based on both the patient's PI and segmental lordosis, allowing a more tailored management of ASD that accounts for pelvic morphology and the natural shape of the spine, and an overcorrection in the proximal LL cannot compensate for a loss of lordosis in the caudal portion of the lumbar spine.

The limitations of the current study are mainly in its retrospective study design and the lack of integrating HRQOL data due to early follow-up. Another limitation due to the retrospective design is the absence of bone mineral density in the analysis. Several studies demonstrated the impact of bone quality on PJK incidence, and further investigation is needed to delineate the impact of bone mineral density on the alignment and, eventually, on the development of PJK.4,14,39 In addition, PJK was analyzed using the radiographic criteria; in clinical practice, clinical and symptomatic PJK is less prevalent than radiographic PJK. Finally, this study assessed the rate of radiographic PJK in early follow-up. While our results probably underestimated the true 2-year PJK rate, it is also well documented that the majority of PJK happens within the first few months following the surgical procedure. . $3,28,37^{2}$

\section{Conclusions}

Restoration of correct alignment in patients with ASD is crucial in achieving an optimal balance and clinical outcomes postoperatively. In addition to the reestablishment of harmony between regional curvatures, the correction of LL should agree with the natural shape of a patient's spine, ultimately avoiding not only unfavorable changes at the upper end of the construct, but also hypercorrection in the proximal segment, which does not compensate for hypocorrection in the distal segment of LL.

\section{References}

1. Ailon T, Sure DR, Smith JS, Shaffrey CI: Surgical considerations for major deformity correction spine surgery. Best Pract Res Clin Anaesthesiol 30:3-11, 2016

2. Bianco K, Norton R, Schwab F, Smith JS, Klineberg E, Obeid I, et al: Complications and intercenter variability of threecolumn osteotomies for spinal deformity surgery: a retrospective review of 423 patients. Neurosurg Focus 36(5):E18, 2014

3. Champain S, Benchikh K, Nogier A, Mazel C, Guise JD, Skalli W: Validation of new clinical quantitative analysis software applicable in spine orthopaedic studies. Eur Spine J 15:982-991, 2006

4. Cho SK, Shin JI, Kim YJ: Proximal junctional kyphosis following adult spinal deformity surgery. Eur Spine J 23:27262736, 2014

5. Diebo B, Liu S, Lafage V, Schwab F: Osteotomies in the treatment of spinal deformities: indications, classification, and surgical planning. Eur J Orthop Surg Traumatol 24 (Suppl 1):S11-S20, 2014

6. Diebo BG, Lafage R, Ames CP, Bess S, Obeid I, Klineberg E, et al: Ratio of lumbar 3-column osteotomy closure: patientspecific deformity characteristics and level of resection impact correction of truncal versus pelvic compensation. Eur Spine J 25:2480-2487, 2016

7. Diebo BG, Lafage V, Varghese JJ, Gupta M, Kim HJ, Ames C, et al: After 9 years of 3-column osteotomies, are we doing better? Performance curve analysis of 573 surgeries with 2-year follow-up. Neurosurgery 83:69-75, 2018

8. Gelb DE, Lenke LG, Bridwell KH, Blanke K, McEnery KW: An analysis of sagittal spinal alignment in 100 asymptomatic middle and older aged volunteers. Spine (Phila Pa 1976) 20:1351-1358, 1995

9. Glassman SD, Bridwell K, Dimar JR, Horton W, Berven S, Schwab F: The impact of positive sagittal balance in adult spinal deformity. Spine (Phila Pa 1976) 30:2024-2029, 2005

10. Glattes RC, Bridwell KH, Lenke LG, Kim YJ, Rinella A, Edwards C II: Proximal junctional kyphosis in adult spinal deformity following long instrumented posterior spinal fusion: incidence, outcomes, and risk factor analysis. Spine (Phila Pa 1976) 30:1643-1649, 2005

11. Hamilton DK, Kanter AS, Bolinger BD, Mundis GM Jr, Nguyen S, Mummaneni PV, et al: Reoperation rates in minimally invasive, hybrid and open surgical treatment for adult 
spinal deformity with minimum 2-year follow-up. Eur Spine J 25:2605-2611, 2016

12. Harrison DE, Harrison DD, Cailliet R, Janik TJ, Holland B: Radiographic analysis of lumbar lordosis: centroid, Cobb, TRALL, and Harrison posterior tangent methods. Spine (Phila Pa 1976) 26:E235-E242, 2001

13. Hostin R, McCarthy I, O'Brien M, Bess S, Line B, BoachieAdjei $\mathrm{O}$, et al: Incidence, mode, and location of acute proximal junctional failures after surgical treatment of adult spinal deformity. Spine (Phila Pa 1976) 38:1008-1015, 2013

14. Hyun SJ, Kim YJ, Rhim SC: Patients with proximal junctional kyphosis after stopping at thoracolumbar junction have lower muscularity, fatty degeneration at the thoracolumbar area. Spine J 16:1095-1101, 2016

15. Inami S, Moridaira H, Takeuchi D, Shiba Y, Nohara Y, Taneichi H: Optimum pelvic incidence minus lumbar lordosis value can be determined by individual pelvic incidence. Eur Spine J 25:3638-3643, 2016

16. Kim HJ, Bridwell KH, Lenke LG, Park MS, Song KS, Piyaskulkaew C, et al: Patients with proximal junctional kyphosis requiring revision surgery have higher postoperative lumbar lordosis and larger sagittal balance corrections. Spine (Phila Pa 1976) 39:E576-E580, 2014

17. Kim HJ, Yagi M, Nyugen J, Cunningham ME, Boachie-Adjei $\mathrm{O}$ : Combined anterior-posterior surgery is the most important risk factor for developing proximal junctional kyphosis in idiopathic scoliosis. Clin Orthop Relat Res 470:1633-1639, 2012

18. Kim YJ, Bridwell KH, Lenke LG, Glattes CR, Rhim S, Cheh G: Proximal junctional kyphosis in adult spinal deformity after segmental posterior spinal instrumentation and fusion: minimum five-year follow-up. Spine (Phila Pa 1976) 33:2179-2184, 2008

19. Kittleson AC, Lim LW: Measurement of scoliosis. Am J Roentgenol Radium Ther Nucl Med 108:775-777, 1970

20. Koller H, Pfanz C, Meier O, Hitzl W, Mayer M, Bullmann V, et al: Factors influencing radiographic and clinical outcomes in adult scoliosis surgery: a study of 448 European patients. Eur Spine J 25:532-548, 2016

21. Lafage R, Bess S, Glassman S, Ames C, Burton D, Hart R, et al: Virtual modeling of postoperative alignment after adult spinal deformity surgery helps predict associations between compensatory spinopelvic alignment changes, overcorrection, and proximal junctional kyphosis. Spine (Phila Pa 1976) 42:E1119-E1125, 2017

22. Lafage R, Schwab F, Challier V, Henry JK, Gum J, Smith J, et al: Defining spino-pelvic alignment thresholds: should operative goals in adult spinal deformity surgery account for age? Spine (Phila Pa 1976) 41:62-68, 2016

23. Lafage V, Schwab F, Patel A, Hawkinson N, Farcy JP: Pelvic tilt and truncal inclination: two key radiographic parameters in the setting of adults with spinal deformity. Spine (Phila Pa 1976) 34:E599-E606, 2009

24. Lowe TG, Kasten MD: An analysis of sagittal curves and balance after Cotrel-Dubousset instrumentation for kyphosis secondary to Scheuermann's disease. A review of 32 patients. Spine (Phila Pa 1976) 19:1680-1685, 1994

25. Maruo K, Ha Y, Inoue S, Samuel S, Okada E, Hu SS, et al: Predictive factors for proximal junctional kyphosis in long fusions to the sacrum in adult spinal deformity. Spine (Phila Pa 1976) 38:E1469-E1476, 2013

26. Moal B, Schwab F, Ames CP, Smith JS, Ryan D, Mummaneni $\mathrm{PV}$, et al: Radiographic outcomes of adult spinal deformity correction: a critical analysis of variability and failures across deformity patterns. Spine Deform 2:219-225, 2014

27. Park P, Wang MY, Lafage V, Nguyen S, Ziewacz J, Okonkwo DO, et al: Comparison of two minimally invasive surgery strategies to treat adult spinal deformity. J Neurosurg Spine 22:374-380, 2015
28. Park SJ, Lee CS, Chung SS, Lee JY, Kang SS, Park SH: Different risk factors of proximal junctional kyphosis and proximal junctional failure following long instrumented fusion to the sacrum for adult spinal deformity: survivorship analysis of 160 patients. Neurosurgery 80:279-286, 2017

29. Protopsaltis T, Schwab F, Bronsard N, Smith JS, Klineberg E, Mundis G, et al: The T1 pelvic angle, a novel radiographic measure of global sagittal deformity, accounts for both spinal inclination and pelvic tilt and correlates with health-related quality of life. J Bone Joint Surg Am 96:1631-1640, 2014

30. Rothenfluh DA, Mueller DA, Rothenfluh E, Min K: Pelvic incidence-lumbar lordosis mismatch predisposes to adjacent segment disease after lumbar spinal fusion. Eur Spine J 24:1251-1258, 2015

31. Roussouly P, Gollogly S, Berthonnaud E, Dimnet J: Classification of the normal variation in the sagittal alignment of the human lumbar spine and pelvis in the standing position. Spine (Phila Pa 1976) 30:346-353, 2005

32. Schwab F, Patel A, Ungar B, Farcy JP, Lafage V: Adult spinal deformity-postoperative standing imbalance: how much can you tolerate? An overview of key parameters in assessing alignment and planning corrective surgery. Spine (Phila Pa 1976) 35:2224-2231, 2010

33. Schwab F, Ungar B, Blondel B, Buchowski J, Coe J, Deinlein D, et al: Scoliosis Research Society-Schwab adult spinal deformity classification: a validation study. Spine (Phila Pa 1976) 37:1077-1082, 2012

34. Schwab FJ, Diebo BG, Smith JS, Hostin R, Shaffrey CI, Cunningham ME, et al: Fine-tuned surgical planning in adult spinal deformity: determining the lumbar lordosis necessary by accounting for both thoracic kyphosis and pelvic incidence. Spine J 14 (11 Suppl):S73, 2014 (Abstract)

35. Smith JS, Klineberg E, Schwab F, Shaffrey CI, Moal B, Ames CP, et al: Change in classification grade by the SRSSchwab Adult Spinal Deformity Classification predicts impact on health-related quality of life measures: prospective analysis of operative and nonoperative treatment. Spine (Phila Pa 1976) 38:1663-1671, 2013

36. Smith JS, Shaffrey E, Klineberg E, Shaffrey CI, Lafage V, Schwab FJ, et al: Prospective multicenter assessment of risk factors for rod fracture following surgery for adult spinal deformity. J Neurosurg Spine 21:994-1003, 2014

37. Smith MW, Annis P, Lawrence BD, Daubs MD, Brodke DS: Early proximal junctional failure in patients with preoperative sagittal imbalance. Evid Based Spine Care J 4:163-164, 2013

38. Stokes IA, Aronson DD, Ronchetti PJ, Labelle H, Dansereau $\mathrm{J}$ : Reexamination of the Cobb and Ferguson angles: bigger is not always better. J Spinal Disord 6:333-338, 1993

39. Yagi M, King AB, Boachie-Adjei O: Incidence, risk factors, and natural course of proximal junctional kyphosis: surgical outcomes review of adult idiopathic scoliosis. Minimum 5 years of follow-up. Spine (Phila Pa 1976) 37:1479-1489, 2012

\section{Disclosures}

The International Spine Study Group (ISSG) is funded through research grants from DePuy Synthes (current), NuVasive (current), K2M (current), Innovasis (past), Biomet (past), and individual donations. Dr. Obeid reports being a consultant for DePuy Synthes and Medtronic; receiving clinical or research support for the study from DePuy Synthes; and receiving royalties from Alphatec Spine, Spineart, and Clariance. Dr. Bess reports being a consultant for K2 and Allosource; receiving clinical or research support for the study from Biomet, DePuy Spine, and Innovasis; being a patent holder for K2; and receiving support of non-study-related clinical or research effort from Medtronic, Stryker, and NuVasive. Dr. Burton reports receiving royalties and research support 
of non-study-related clinical or research effort from DePuy. Dr. Smith reports being a consultant for Zimmer Biomet, NuVasive, and Cerapedics; receiving royalties from Zimmer Biomet; receiving support of non-study-related clinical or research effort from DePuy Synthes/ISSG; receiving clinical or research support for the study from DePuy Synthes/ISSG; receiving fellowship support from NREF and AO Spine; and receiving an honorarium for teaching from K2M. Dr. Hostin reports being a consultant for DePuy; and receiving support of non-study-related clinical or research effort from NuVasive, Seeger, DJO, DePuy, and K2M. Dr. Shaffrey reports being a consultant for Medtronic, NuVasive, Zimmer-Biomet, K2M, and Stryker; direct stock ownership of $\mathrm{NuVasive}$; and being a patent holder and receiving royalties from Medtronic, NuVasive, and Zimmer-Biomet. Dr. Ames reports being a consultant for DePuy, Medtronic, and Stryker; being a patent holder for Fish \& Richardson, P.C.; and receiving royalties from Stryker and Biomet Spine. Dr. Klineberg reports direct stock ownership in Nemaris, Inc.; being a consultant for NuVasive; receiving speaking/teaching arrangements from DePuy Spine, $\mathrm{K} 2 \mathrm{M}$, and MSD; and receiving support of non-study-related clinical or research effort from DePuy Spine, Stryker, NuVasive, and K2M (paid through ISSGF). Dr. Schwab reports direct stock ownership in Nemaris, Inc.; support of non-study-related clinical or research effort from DePuy Spine, NuVasive, Stryker, and
$\mathrm{K} 2 \mathrm{M}$; and being a consultant for and receiving speaking/teaching arrangements from Zimmer-Biomet, Medicrea, MSD, K2M, and NuVasive. Dr. V. Lafage reports direct stock ownership in Nemaris, Inc.; being a consultant for NuVasive; receiving support of non-study-related clinical or research effort from DePuy Spine, K2M, Stryker, and NuVasive (paid through ISSGF); and speaking/ teaching arrangements from DePuy Spine, NuVasive, MSD, and K2M.

\section{Author Contributions}

Conception and design: V Lafage, R Lafage. Acquisition of data: $\mathrm{V}$ Lafage, R Lafage. Analysis and interpretation of data: R Lafage. Drafting the article: V Lafage, $R$ Lafage. Critically revising the article: R Lafage. Reviewed submitted version of manuscript: all authors. Approved the final version of the manuscript on behalf of all authors: V Lafage. Statistical analysis: V Lafage, R Lafage. Administrative/technical/material support: V Lafage, Obeid, Liabaud, Bess, Burton, Smith, Jalai, Hostin, Shaffrey, Ames, Kim, Klineberg, Schwab.

\section{Correspondence}

Virginie Lafage: Hospital for Special Surgery, New York, NY. virginie.lafage@gmail.com. 